\title{
Płaczac po norwesku. \\ Serial Skam jako opowieść transmedialna dla międzynarodowej publiczności
}

\author{
MAŁGORZATA MĄCZKO \\ Uniwersytet Jagielloński w Krakowie
}

\begin{abstract}
Mączko Małgorzata, Płacząc po norwesku. Serial Skam jako opowieść transmedialna dla międzynarodowej publiczności [Crying in Norwegian. Skam as transmedia storytelling for international audiences]. "Images" vol. XXVIII, no. 37. Poznań 2020. Adam Mickiewicz University Press. Pp. 328-337. ISSN 1731-450X. DOI 10.14746/i.2020.37.19.

The article aims to analyse the phenomenon of a Norwegian Internet-TV show for teenage audiences, Skam (2015-2017). The transmedia storytelling used in this production resulted in unforeseen international acclaim, subsequently leading to the creation of local remakes of the series. The article will outline the main issues that the show has dealt with, as well as the immersion-building narrative solutions used by the creators. Moreover, it will discuss Skam's reception by Norwegian and international audiences, and suggest potential directions for the future development of this format.
\end{abstract}

KEYWORDS: Skam, transmedia storytelling, convergence culture, immersion

Można odnieść wrażenie, że o kształcie współczesnego świata seriali decyduje zaledwie garstka graczy - amerykańskie stacje telewizyjne, wielkie konglomeraty medialne oraz dostępne niemal wszędzie platformy streamingowe. Taka diagnoza, choć powierzchowna, nie jest bezpodstawna. Nietrudno bowiem dostrzec, że w XXI wieku o żywotności i popularności serialu nie decyduje jedynie jego wartość artystyczna, lecz cały splot okoliczności ekonomicznych i medialnych, który faworyzuje duże wytwórnie i sprawia, że mniejsze produkcje mają nikłe szanse na przebicie się do szerokiej publiczności. Nie oznacza to jednak, że dzisiaj nie powstają już wartościowe seriale, które realizują pomysły niezależnych twórców i wyróżniają się oryginalnym podejściem do gatunków telewizyjnych lub lokalną specyfiką. Trudniej jest im jednak osiągnąć sukces, gdy muszą konkurować z dziełami, za którymi stoją medialni giganci, mający do dyspozycji niemal nieograniczone zasoby finansowe i ugruntowaną pozycję na rynku.

$\mathrm{Na}$ tym większe uznanie zasługują dzieła, którym udaje się trafić do publiczności i wypełnić konkretną niszę mimo braku tak imponującego produkcyjno-dystrybucyjnego zaplecza. W ostatnich latach fenomenem na gruncie serialu młodzieżowego stał się skromny norweski tytuł, który zdobył serca nastolatków na całym świecie i doczekał się licznych lokalnych remakeów. Wyprodukowany przez publiczną telewizję serial Skam (2015-2017) okazał się niespodziewanym hitem, na którego sukces złożyło się kilka czynników. Połączenie innowacyjnej, transmedialnej narracji, uniwersalnych treści oraz wrażenia autentyzmu sprawiło, że tej niepozornej produkcji udało się trafić nie tylko do norweskiego odbiorcy. Szybko pojawiły się jednak trudności wynikające, paradoksalnie, właśnie ze zbyt dużej popularności serialu, a dostęp do treści stał się utrudniony. Finał Skam, zdaniem wielu odbiorców przedwczesny, pozostawił niedosyt, otwierając jednocześnie możliwość nowych interpretacji, kontynuacji oraz remiksów opowiedzianych w ciągu czterech sezonów historii. Przykład tego serialu posłuży do diagnozy nowych trendów w produkcjach telewizyjnych przeznaczonych dla młodych 
odbiorców oraz pozwoli postawić hipotezy na temat ich przyszłości.

\section{Droga do sukcesu}

Za sterami serialu Skam stanęła młoda reżyserka i scenarzystka Julie Andem. Już wcześniej pracowała ona dla norweskiego publicznego nadawcy telewizyjnego i radiowego NRK, od 2012 roku pomagając $\mathrm{w}$ realizacji takich seriali, jak Sara (2008-2009), MIA (2010-2012) i Jenter (nor. Dziewczyny, 2013-2017). Za ich produkcję odpowiadała stacja NRK Super, której programy są skierowane głównie do młodych odbiorców, dopiero wkraczających w nastoletniość. Wymienione powyżej seriale, opowiadając o perypetiach 12 -letnich bohaterek, stawiały jednocześnie pierwsze kroki na gruncie prowadzonej w Internecie narracji transmedialnej. Dopiero testowano możliwości takiej formy podawania widzom treści, wykorzystując w odcinkach klipy z rozmów wideo oraz prowadząc blogi i konta bohaterek na Instagramie.

Dobre przyjęcie tych produkcji sprawiło, że norweski nadawca zapragnął dotrzeć również do nieco starszej widowni. Docelową grupę odbiorców nowego serialu miały stanowić głównie 16-letnie dziewczęta, a jego produkcją zajęła się NRK $P_{3}$, czyli publiczna stacja radiowa skierowana do nastolatków. Julie Andem po raz pierwszy przyjęła wtedy rolę showrunnerki i od podstaw wykreowała świat serialu Skam. Pracując nad scenariuszem pierwszego sezonu, twórczyni zgłębiała młodzieżową kulturę i przeprowadziła serię długich rozmów $\mathrm{z}$ norweskimi nastolatkami. Te szczegółowe wywiady miały zapewnić serialowi wiarygodność oraz uczulić Andem na najważniejsze problemy, z jakimi mierzą się obecnie młodzi ludzie. Reżyserka była świadoma, że Skam będzie musiało rywalizować o względy widzów z dużymi amerykańskimi produkcjami. Siłą jej serialu miała być zatem właśnie wierność norweskim realiom, mająca umożliwić większą identyfikację odbiorców z przeżyciami bohaterów[1].

Premiera serialu nie została poprzedzona kampanią reklamową, ponieważ twórcom zależało na tym, by sami odbiorcy dzielili się między sobą informacjami o serialu za pomocą mediów społecznościowych[2]. Mimo braku promocji już pierwszy sezon zyskał popularność w Norwegii, a nagły przyrost międzynarodowej publiczności w 2016 roku potwierdził niezwykłą skuteczność tej strategii marketingowej. Odzew fanów od samego początku istnienia serialu miał kluczowe znaczenie dla jego twórców, którzy nie chcieli, by opowiadane przez nich historie istniały jedynie w medialnej próżni.

\section{Formuła serialu}

By zrozumieć fenomen serialu Skam, należy najpierw pochylić się nad samym zjawiskiem narracji transmedialnej, której znaczenie we współczesnych mediach nieustannie wzrasta. Sam termin jest łączony w badaniami Henry'ego Jenkinsa, który opisywał zmiany w sposobie cyrkulacji mediów oraz nowe sposoby, w jakie dzisiejsi odbiorcy wchodzą z nimi w interakcję. Tytułowa kultura konwergencji to w jego ujęciu „przepływ treści pomiędzy różnymi platformami medialnymi, współpraca różnych przemysłów medialnych oraz migracyjne zachowania odbiorców mediów, którzy dotrą niemal wszędzie, poszukując takiej rozrywki, na jaką mają ochotę"[3]. W ciągu trzynastu lat, które upłynęły od premiery książki Jenkinsa, świat zdążył się przekonać, jak trafne okazały się jego stwierdzenia.

Skam wręcz modelowo wpisuje się w zaproponowaną przez Jenkinsa definicję opowiadania transmedialnego, będącego „wielowątkową i zróżnicowaną historią, która odsłaniana jest na różnych platformach medialnych, przy czym każde medium ma swój oddzielny wkład $\mathrm{w}$ tworzenie i rozwijanie fikcyjnego świata" [4].

[1] J.I. Fandalen, Nerven i "Skam" skal vore sterk og relevant, „Rushprint” 4.04.2016, <https:// rushprint.no/2016/04/nerven-i-skam-skal-vaere-sterk-og-relevant/>, dostęp: 16.08.2020.

[2] Ibidem.

[3] H. Jenkins, Kultura konwergencji. Zderzenie starych i nowych mediów, przeł. M. Filiciak, Warszawa 2007 , s. 9.

[4] Ibidem, s. 26o. 
Młodzi widzowie, w pełni,,zanurzeni we współczesnej kulturze medialnej, $\mathrm{z}$ chęcią podejmowali taką grę, a twórcy konsekwentnie i z dbałością o szczegóły konstruowali rozgrywającą się w różnych mediach narrację". Warto również zauważyć, że w Skam podział między producentami treści a jej konsumentami ulega zatarciu. Sam Jenkins, pisząc o kulturze konwergencji, sygnalizował, że te dwie strony wchodzą ze sobą w nierówną interakcję[5]. W przypadku tego serialu aktywni odbiorcy mieli duży wpływ nie tylko na jego przekaz i treść poszczególnych odcinków, ale odegrali też kluczową rolę w rozpowszechnianiu Skam, przyjmując rolę tak zwanych prosumentów.

By właściwie ocenić znaczenie, jakie dla sukcesu serialu miała jego transmedialność, należy najpierw zrozumieć zasady jego dystrybucji. Nowy sezon Skam rozpoczynał się zwykle stosunkowo niepozornie - w dzień premiery udostępniano widzom klip wideo lub innego rodzaju materiały medialny, pozwalający zorientować się, kto jest głównym bohaterem, i jednocześnie zarysowując główne wątki danego sezonu. Te początkowe treści pojawiały się zazwyczaj w soboty, a następnie przez resztę tygodnia odbiorców karmiono kolejnymi materiałami, poszerzającymi ich wiedzę. Podstawowym źródłem treści związanych z serialem była specjalnie do tego przeznaczona strona www.skam.p3.no. Pojawiały się tam wszystkie elementy składające się na narrację serialu: klipy wideo, zrzuty ekranu rozmów między bohaterami $\mathrm{w}$ mediach społecznościowych oraz linki do nowych postów bohaterów na Instagramie.

Krótkie, kilkuminutowe klipy udostępniane były w pozornie realnym czasie, a więc jeśli dane wydarzenia $\mathrm{w}$ świecie serialu miały miejsce w poniedziałek o godzinie 13:05, to dokładnie tego dnia i o tej godzinie nagranie trafiało na stronę serialu. Koniec danego odcinka wyznaczał piątkowy klip, często pełen spektakularnych zajść - początek weekendu bywał w życiu nastoletnich bohaterów szczególnie intensywny.

[5] Ibidem, s. 9 .
Ten tygodniowy cykl powtarzał się aż do końca sezonu, trwającego od 10 do 12 odcinków. Warto zaznaczyć, że w poszczególnych sezonach zdarzały się dni, kiedy na stronę serialu nie trafiały żadne nowe materiały, budząc spekulacje fanów, próbujących dociec fabularnych źródeł takiej sytuacji.

Ponadto $\mathrm{z}$ udostępnionych w ciągu tygodnia klipów powstawał pełen odcinek, trwający około 25-30 minut. W tej ujednoliconej formie był on emitowany w piątkowe wieczory na antenie stacji NRK3, skierowanej przede wszystkim do nastoletnich odbiorców.

Bezpośrednią konsekwencją opisanego powyżej sposobu dystrybucji serialu są dwa możliwe modele jego odbioru. Nie tylko zakładają one użycie różnych mediów, ale skutkują także nierównomiernym stopniem poinformowania widzów, którzy stosują odmienne modele odbioru.

Pierwszy model zakłada odbiór narracji transmedialnej w sposób, w jaki pierwotnie powstawała, a więc $\mathrm{w}$ przestrzeni różnych mediów. Miało być to dominujące podejście, zwłaszcza wśród odbiorców z docelowej grupy wiekowej. Taka metoda podawania treści koresponduje bowiem ze sposobem, w jaki nastoletni widzowie konsumują obecnie przekazy medialne. Skam udało się wpasować w to, jak młode pokolenie współcześnie funkcjonuje - wielokanałowo i wielowątkowo. Serial kierowano przede wszystkim do równolatków jego bohaterów, a więc młodzieży urodzonej u progu XXI wieku. Roczniki otwierające pokolenie, o którym obecnie najczęściej mówi się jako o Gen Z, to osoby, które od najmłodszych lat były zanurzone w świecie nowych mediów. Często pamiętają jeszcze wynalazki poprzedniej epoki, jednak sami nie musieli z nich korzystać, a Internet to dla nich nie ciekawostka czy droga zabawka, ale podstawowe narzędzie komunikacji. W takiej roli zostało ono również wykorzystane w Skam - zarówno na poziomie fabuły, jak i jej dystrybucji. Tylko odbiór transmedialny pozwalał na pełne doświadczanie narracji i głęboką immersję, która była jedną z intencji twórców. Widz musiał wcielić się rolę „utalento- 
wanego internetowego stalkera”[6], by czerpać maksymalną satysfakcję odbiorczą.

Budowanie iluzji realności przedstawianych wydarzeń było dla nich na tyle ważne, że młodzi aktorzy w czasie realizacji serialu nie udzielali wywiadów i nie mieli publicznych wystąpień. Dopiero po zakończeniu realizacji wszystkich sezonów zdjęto z nich embargo i mogli zacząć wchodzić w częstsze interakcje $\mathrm{z}$ fanami, między innymi na konwentach fanowskich.

Drugi model odbioru był bliższy bardziej tradycyjnym sposobom konsumowania treści medialnych. Część widzów oglądała serial jedynie w formie cotygodniowych odcinków, emitowanych w telewizji. Odbiorcy, dla których było to jedyne źródło wiedzy o fabule, musieli się liczyć z dużo niższym horyzontem poinformowania. Choć poszczególne klipy były zrozumiałe bez znajomości treści zamieszczanych na kontach bohaterów w mediach społecznościowych, to w tym modelu odbioru widzom umykały niektóre niuanse. Proponując widzom tak rozbudowaną narrację transmedialną, twórcy muszą się jednak liczyć z tym, że projektowany przez nich odbiór multimedialnych treści nie zostanie przyjęty przez niektórych widzów, którzy pozostaną wierni konwencjonalnym postawom odbiorczym.

\section{Bohaterowie na XXI wiek}

W ciągu niecałych dwóch lat, między wrześniem 2015 roku a czerwcem 2017, powstały aż cztery sezony Skam. Każdy z nich poświęcony był przeżyciom innego głównego bohatera z tej samej grupy znajomych. Niektóre postaci drugoplanowe i epizodyczne powracały w każdym sezonie, inne pojawiały się tylko w wątku dotyczącym wybranego bohatera. Istotnym elementem serialu był prawie zupełny brak dorosłych postaci - licealiści często mieszkali sami lub mieli rzadki kontakt ze swoimi rodzicami. Jedynie pojawiająca się co jakiś czas szkolna pielęgniarka odpowiadała na trapiące bohaterów poważniejsze pytania. Wszystkie inne problemy, na które napotykali bohaterowie, musieli rozwiązywać już na własną rękę lub przy wsparciu swoich równolatków. Serialowi udawało się jednak balansować między różnymi tonami wypowiedzi, wprowadzając często elementy komediowe dla zrównoważenia trudniejszych treści.

Pierwszy sezon Skam wydaje się najbardziej zachowawczy, wręcz niepozorny. Jego główną bohaterką jest Eva, a dominującym tematem relacje z jej chłopakiem, Jonasem. Pojawiają się takie uniwersalne motywy, jak przyjaźń, odtrącenie przez rówieśników, samotność i poszukiwanie własnego miejsca na świecie. Świeżość i wiarygodność fabuły wystarczyły, by przyciągnąć norweską publiczność i nakłonić stację do stworzenia kolejnych sezonów.

Kolejną główną bohaterką jest Noora, jedna z nowych przyjaciółek Evy. Poświęcony jej sezon udowodnił, że Skam, choć zdaje się "tylko” serialem dla nastolatek, ma ambicję, by komentować wyzwania współczesności i obrazować zmagania młodzieży z problemami, o których dorośli debatują na pierwszych stronach gazet. Obok typowych tematów, takich jak miłosne zawirowania, zdrady i próby budowania zaufania, pojawia się bowiem wątek napaści seksualnej. Andem chwalono za niezwykłe wyczucie i powagę, $\mathrm{z}$ jakimi potraktowała ten motyw, wpisując się tym samym w ważną debatę na temat przemocy seksualnej wobec kobiet i wpływu, jaki ma ona na dalsze życie ofiar[7]. Drugi sezon Skam docenili również przedstawiciele norweskich organizacji walczących z przemocą seksualną[8].

[6] D.T. Max, "SKAM", the radical teen drama that unfolds one post at a time, „New Yorker" 11.06.2018, <https://www.newyorker.com/magazine/2018/06/18/skam-the-radical-teen-drama-that-unfolds-one-post-at-a-time>, dostęp: 16.08.2020.

[7] A. Leszkiewicz, Skam: how one Norwegian teen drama got the TV depiction of sexual assault right, „New Statesman” 16.03.2017, < https://www. newstatesman.com/culture/tv-radio/2017/03/ skam-how-one-norwegian-teen-drama-got-tv-depiction-sexual-assault-right>, dostęp: 16.08.2020. [8] K.K. Jørgensen, Mener „Skam” burde vere pensum, „NRK” 23.05.2016, <https://www.nrk. no/livsstil/mener-_skam_-burde-vaere-pensum-1.12959025>, dostęp: 16.08.2020. 
Dopiero trzeci sezon serialu przyciągnął pokaźną liczbę zagranicznych odbiorców i uczynił ze Skam międzynarodowy hit. Opowiada on o Isaku, dawnym przyjacielu Evy, który poznaje nowego ucznia szkoły Hartvig Nissen, Evena. Główny bohater zaczyna odkrywać swoją orientację seksualną i musi poradzić sobie $\mathrm{z}$ wymaganiami otoczenia i balastem tak zwanej obowiązkowej heteroseksualności (ang. compulsory heterosexuality). Wraz z rozwojem akcji wprowadzony zostaje również wątek problemów psychicznych, dotykających jego najbliższych: matkę i ukochanego.

Ostatni sezon został poświęcony Sanie, przyjaciółce dwóch pierwszych bohaterek i koleżance z ławki Isaka. Dopiero przyjęcie w serialu perspektywy młodej muzułmanki pozwala w pełni zdać sobie sprawę z izolacji i odtrącenia, jakich bohaterka doświadcza ze względu na swoje wyznanie nawet w gronie najbliższych znajomych. I tym razem Andem nie stroni od ważkich tematów, już w pierwszych minutach nawiązując do bieżącej sytuacji społeczno-politycznej: na ekranie najpierw pojawia się wystąpienie Donalda Trumpa, potem plakat $\mathrm{z}$ marszu kobiet $\mathrm{w}$ dniu jego inauguracji na prezydenta, przedstawiający kobietę w hidżabie $\mathrm{z}$ amerykańskiej flagi, a wreszcie także ujęcia próbujących przekroczyć granicę uchodźców. Bohaterka będzie musiała stawić czoła codziennym przejawom islamofobii oraz próbom pogodzenia swojej głębokiej wiary z życiem przeciętnej, norweskiej nastolatki, które staną się szczególnie trudne, gdy zakocha się w niewierzącym chłopaku.

Czwarty sezon krytykowano jednak za odciąganie uwagi od głównej bohaterki i zbytnie skupienie na losach innych postaci[9]. Końcowe klipy poświęcono ponadto bohaterom, którzy

[9] A. Leszkiewicz, Skam, interrupted: why is the phenomenally popular teen drama ending before its peak?, „New Statesman” 23.06.2017, $<$ https://www.newstatesman.com/culture/tv-radio/2017/o6/skam-interrupted-why-phenomenally-popular-teen-drama-ending-its-peak>, dostęp: 16.08.2020.

[10] Ibidem. nie doczekali się własnego sezonu, dając widzom posmak tego, jak mógłby wyglądać serial, gdyby miał trwać dłużej.

Pierwszy sezon otwierała narracja $z$ offu, w której jeden z bohaterów czytał szkolne wypracowanie o niesprawiedliwościach kapitalistycznego ustroju, podczas gdy na ekranie w coraz większym tempie przeskakiwały obrazy bawiącej się bez opamiętania młodzieży. Podobny zabieg powraca $\mathrm{w}$ finale, choć tym razem odczytywany jest list, w którym przyjaciele dziękują Sanie. Z czasem monolog przeradza się jednak w odezwę do widzów. Obok urywków z klipów, które nie trafiły do serialu, pojawiają się fragmenty nagrań $\mathrm{z}$ bieżących światowych kryzysów. Na koniec kamera przyjmuje perspektywę widza oglądającego Skam na komputerze. Pojawiają się ujęcia komentarzy, które odbiorcy zostawiali pod poszczególnymi klipami - zarówno tych hejterskich, jak i pozytywnych. Głos z offu przypomina: „Strach się rozprzestrzenia. Ale, na szczęście, miłość również”. Tymi słowami Skam żegna się z widzami na zawsze.

$\mathrm{Na}$ trzy dni przed rozpoczęciem czwartego sezonu Julie Andem ogłosiła na swoim Instagramie, że będzie to jednocześnie ostatni sezon całego serialu. Informacja była dla fanów serii sporym zaskoczeniem, ponieważ już od pierwszego sezonu sygnalizowano, że Skam będzie towarzyszył bohaterom aż do końca liceum - na świętowanie ostatniego tygodnia szkoły bohaterowie szykowali się już od pierwszego semestru. Chociaż twórczyni nigdy nie podała konkretnych przyczyn tego przedwczesnego finiszu serii, to część fanów przypuszczała, że serial stał się ofiarą własnego sukcesu[10].

\section{Recepcja w Norwegii i początki międzynarodowej popularności}

Zanim Skam stał się międzynarodowym fenomenem, zyskał uznanie rodzimej widowni. Już pierwszy sezon cieszył się stosunkowo dużą popularnością, łamiąc ówczesne rekordy w popularności serialu online na platformie stacji NRK. Stały napływ nowych odbiorców sprawił, że w szczytowym momencie oglądal- 
ność serialu w 5-milionowej Norwegii wynosiła niemal 800 tysięcy widzów[11]. W 2016 i 2017 roku Skam doceniono również podczas rozdania norweskich nagród telewizyjnych, Gullruten, gdzie stworzony przez Andem serial zdobył kilka statuetek, w tym za scenariusz i reżyserię.

Skam zagościł również na stałe w norweskim dyskursie publicznym, i to nie tylko dzięki częstej obecności w rozmowach nastoletnich widzów. Grono odbiorców okazało się bowiem bardzo różnorodne, co ilustruje sytuacja $\mathrm{z}$ obrad nad budżetem Oslo pod koniec 2016 roku. Jeden z polityków powoływał się wtedy na trudną sytuację mieszkaniową młodych bohaterów serialu, a przewodnicząca posiedzenia musiała upominać się o ograniczenie nawiązań do Skam[12].

Ponadto, kiedy na początku 2018 roku, a więc ponad pół roku po zakończeniu emisji serialu, brytyjska para książęca przybyła do Norwegii z oficjalną wizytą, w programie znalazły się między innymi odwiedziny w szkole Hartvig Nissen. Książę William wraz z małżonką spotkał się tam z częścią obsady Skam oraz prawdziwymi uczniami, by porozmawiać z młodzieżą o wadze przekazu, jaki niósł ze sobą serial[13].

Dowodów na popularność serialu w rodzimej Norwegii zatem nie brakuje. O wiele ciekawszym i bardziej skomplikowanym zjawiskiem jest jednak sposób, w jaki Skam trafił na arenę międzynarodową. Nie wydarzyło się to od razu, kiedy tylko początkowe odcinki serialu zaczęły przyciągać uwagę norweskiej opinii publicznej. Stopniowy przyrost liczby fanów nastąpił bowiem dopiero w 2016 roku, a w trakcie emisji trzeciego sezonu oglądalność osiągnęła szczytowy poziom[14]. Młodzi widzowie „pocztą pantoflową" na internetowych forach przekazywali dalej informację o intrygującej, niszowej produkcji. Można przypuszczać, że znacząca była tematyka odcinków poświęconych Isakowi, odpowiadająca na zapotrzebowanie nastolatków na mądrze i realistycznie opowiedziane historie o queerowych bohaterach, których w mediach wciąż brakuje.

\section{Bieg z przeszkodami}

Wraz z napływem międzynarodowej publiczności pojawił się cały szereg problemów, z którymi musieli zmierzyć się zarówno fani, jak i producenci serialu. Dosyć szybko palącą kwestią stała się bariera językowa. Widzowie z całego świata (Skam oglądano nie tylko w Europie, ale również w Stanach Zjednoczonych, Kanadzie i Ameryce Południowej) jesienią 2016 roku promowali na Twitterze hashtag \#WeNeedEnglishSubsForSkam (ang. potrzebujemy angielskich napisów do Skam). Po kilku dniach stacja NRK, również na Twitterze, zamieściła odmowną odpowiedź, tłumacząc, że serial jest skierowany przede wszystkim do norweskiej młodzieży i choć cieszy ich duże zainteresowanie, to nie udostępnią go po angielsku[15]. Jako kolejny powód podano później również zawarte na potrzeby serialu umowy licencyjne na muzykę, które obejmowały jedynie norweski rynek i ułatwienie zagranicznej publiczności dostępu do Skam mogłoby je naruszać[16].

[11] N. Woldsdal, I. Michelsen, Skam slår alle rekorder, „NRK” 21.12.2016, <https://www.nrk. no/kultur/skam-slar-alle-rekorder-1.13282929>, dostęp: 16.08.2020.

[12] O. Eggesvik, Nå har Oslo fått sitt første rødgrønne budsjett på 19 år, „Aftenposten” 7.12.2016, <https://www.aftenposten.no/osloby/ $\mathrm{i} / 8 \mathrm{M} 7 \mathrm{bW} /$ naa-har-oslo-faatt-sitt-foerste-roedgroenne-budsjett-paa-19-aar>, dostęp: 16.08.2020. [13] I. Tired, I. Fjelletveit, Skam-skuespillerne møtte William og Kate. Men hertugparet hadde neppe sett serien, „Aftenposten” 2.02.2018, $<$ https://www.aftenposten.no/verden/i/MgLRkK/ skam-skuespillerne-moette-william-og-kate-men-hertugparet-hadde-neppe-sett-serien>, dostęp: 16.08.2020.

[14] T. Taylor, How Skam's Isak and Even revolutionized teen $T V$, „Interview Magazine” 6.10.2017, $<$ https://www.interviewmagazine.com/film/ skams-isak-even-revolutionized-teen-tv>, dostęp: 16.08.2020.

[15] Post na oficjalnym koncie stacji NRK na portalu Twitter z 1 listopada 2016 r., <https:// twitter.com/NRKno/status/793557575627313157>, dostęp: 16.08.2020.

[16] K.S. Nilsen, C. Elnan, Why NRK can't translate Skam, „NRK” 2.11.2016, <https:// 
Młodzi odbiorcy znaleźli jednak kilka sposobów na obejście tych ograniczeń. Norwescy nastolatkowie, chcący dzielić się serialem z obcojęzycznymi rówieśnikami, przygotowywali własne tłumaczenia. Kiedy udostępniane w serwisie YouTube przetłumaczone klipy zaczęto sukcesywnie usuwać, fani umieszczali je w formie tekstowej na Tumblrze. Niektórzy, mimo ostrzeżeń ze strony NRK, udostępniali klipy z wgranymi napisami na własnych dyskach Google i dzielili się linkami z innymi odbiorcami. Co istotne, użytkownicy znający norweski tłumaczyli nie tylko same klipy wideo, ale również wszystkie pozostałe treści składające się na transmedialną opowieść o życiu bohaterów. Tym samym specyfika narracji mogła zostać zachowana i fani z całego świata doświadczali Skam w podobny sposób, jak norweska docelowa publiczność, choć z lekkim przesunięciem czasowym - na tłumaczenia trzeba było mimo wszystko poczekać od kilku do kilkudziesięciu minut. Działania publiczności, choć sprzeczne z prawem, sprawiły, że społeczność fanowska mogła działać ponad podziałami geograficznymi czy barierami językowymi.

Nielegalne rozpowszechnianie serialu wśród odbiorców z terytoriów nieobjętych umowami licencyjnymi nie uszło uwadze wytwórni muzycznych. W styczniu 2017 roku, a więc $\mathrm{w}$ przerwie między trzecim a czwartym sezonem, stacja NRK objęła wszystkie klipy wideo dostępne na stronie serialu tak zwanym geoblockiem, uniemożliwiając ich wyświetlanie osobom znajdującym się poza Norwegią[17]. W repertuarze zagranicznych fanów Skam obok nieautoryzowanych tłumaczeń szybko pojawiły

www.nrk.no/kultur/why-nrk-can_t-translate-skam-1.13208362>, dostęp: 16.08.2020.

[17] Informacja Działu Komunikacji na stronie stacji NRK z 13 stycznia 2017 r., <https://www. nrk.no/informasjon/geoblocking-of-the-drama-series-skam-1.13321219>, dostęp: 16.08.2020. [18] L. Bartleet, Why you should be watching Skam, Tumblr's most talked-about TV show of 2017, „NME” 6.12.2017, <https://www.nme.com/ blogs/tv-blogs/watching-skam-tumblrs-talked-tv-show-2017-2168642>, dostęp: 16.08.2020. się zatem również usługi VPN, umożliwiające obchodzenie kolejnych ograniczeń nałożonych przez NRK. Mimo coraz większych trudności z odbiorem fani pozostali wierni serialowi także podczas ostatniego sezonu.

\section{Skamily}

Wokół serialu w mediach społecznościowych wytworzyła się duża społeczność fanowska, często określająca się mianem „Skamily”. Ważnymi przestrzeniami dla tego fandomu stały się Tumblr, Twitter oraz YouTube. To na tych platformach, w postach i komentarzach, rozgrywała się większość rozmów o serialu. Potwierdzeniem popularności Skam może być chociażby zajęte przez serial pierwsze miejsce na liście najaktywniejszych serialowych fandomów na Tumblrze w roku 2017, kiedy to norweska produkcja zdeklasowała takie hity jak Gra o tron i Stranger Things[18]. W okresie szczytowej popularności serialu powstawała również bardzo duża twórczości fanowskiej - fanartów, fanfików oraz własnych remiksów wybranych scen $\mathrm{z}$ serialu. Oryginalne treści kreowane przez fanów często docierały bezpośrednio do twórców i zdarzało się, że Andem czerpała $\mathrm{z}$ nich inspirację, chociażby odtwarzając w Skam sceny z rysunków fanki, które trafiły do sieci kilka miesięcy wcześniej.

Jak zostało wspomniane, aktywność fanów była dla tego serialu kluczowa na każdym etapie jego istnienia. Nie powinna zatem dziwić żywotność jego fandomu oraz niezwykle mocne zaangażowanie publiczności, wynikające z kilku nakładających się na siebie czynników. Jednym $\mathrm{z}$ nich była $\mathrm{z}$ pewnością wspomniana na początku rozdziału narracja transmedialna, nadążająca za sposobem, w jaki młodzi użytkownicy konsumują media, oraz związana z nią głęboka immersja i wrażenie realności wydarzeń i postaci. Ponadto, fanom towarzyszyło poczucie wspólnoty, dodatkowo wzmacniane wspólnym przełamywaniem ograniczeń i poczuciem wyjątkowości odbioru popularnego, choć i tak stosunkowo mało znanego serialu. Publiczność przyjmowała aktywną rolę prosumentów, co wpływało zarówno na budowanie fandomu, jak i sukces samego serialu. 


\section{Nowe twarze, stare historie}

Popularność, a także przedwczesne zakończenie Skam sprawiły, że wśród publiczności pozostał niedosyt, a zagraniczni producenci dostrzegli szansę na powtórzenie sukcesu norweskiego serialu. Niedługo po tym, jak Andem ogłosiła, że nie powstaną kolejne sezony oryginalnej wersji programu, pojawiły się doniesienia, że twórczyni zajmie się przygotowaniem jego amerykańskiej adaptacji. Uzgodnienia dotyczące wykorzystania norweskiego formatu zostały poczynione jeszcze zimą 2016 roku, a realizacją nowej wersji miała zająć się kierowana przez Simona Fullera wytwórnia XIX Entertainment[19]. W listopadzie 2017 roku Andem zamieściła na swoim Instagramie wiadomość o castingu do amerykańskiej adaptacji oraz poinformowała, że przyjmie w nim rolę scenarzystki i reżyserki, nie chcąc jeszcze rozstawać się ze Skam. Wyreżyserowany przez Andem pierwszy sezon Skam Austin pojawił się na stronie usługi Facebook Watch wiosną 2018 roku, natomiast drugi, za który odpowiadał już inny reżyser, udostępniono na platformie rok później. W momencie powstawania tego artykułu nie podano jeszcze informacji o premierze ewentualnego trzeciego sezonu.

Amerykańska wersja Skam to nie jedyny remake serialu, choć ze względu na zaangażowanie Andem to właśnie $\mathrm{z}$ nim fani wiązali duże nadzieje. Między lutym a listopadem 2018 roku swoje premiery miało jeszcze sześć innych lokalnych wersji Skam: francuska, niemiecka, włoska, hiszpańska, holenderska i belgijska. Oryginalny serial miał odpowiadać przede wszystkim na potrzeby norweskich nastolatków, lecz wraz z napływem międzynarodowej publiczności stało się jasne, że poruszane zagadnienia są bardziej uniwersalne. Tłumacząc decyzję o sprzedaży formatu do innych krajów, Andem zwracała uwagę, że wszędzie „istnieje potrzeba, by poruszać takie zagadnienia jak problemy psychiczne, molestowanie seksualne czy orientacja seksualna"[20]. Nie dziwi zatem, że historie przedstawiane $\mathrm{w}$ remake'ach zaadaptowano bezpośrednio z wersji norweskiej, gdzie już raz się sprawdziły. Choć zmieniały się imiona postaci, to dotycząca ich fabuła była stosunkowo wiernym przepisaniem wątków z oryginału. Do najbardziej znaczących zmian można zaliczyć wariacje w odpowiednikach sezonu trzeciego: pojawienia się pary lesbijskiej w wersji hiszpańskiej oraz transpłciowego chłopaka w wersji niemieckiej.

Każdy z remakeów wykorzystuje również model dystrybucji opracowany przez NRK, choć, ze względu na dynamikę rozwoju mediów społecznościowych i konieczność pozostania na bieżąco z młodzieżowymi trendami, zmieniają się platformy, na których toczy się transmedialna narracja. W spomniane już Skam Austin do dystrybucji wykorzystuje Facebook Watch, a inne wersje pojawiają się YouTube. Podobnie jak w przypadku oryginału, konieczne jest stosowanie usługi geoblockingu, a w przypadku nieanglojęzycznych wersji wciąż potrzeba tłumaczeń fanowskich. Warto również zauważyć, że w przeciwieństwie do oryginału, niektóre adaptacje powstają bez udziału tradycyjnych stacji telewizyjnych.

Nowi bohaterowie coraz częściej rozmawiają na WhatsAppie, a widzowie wersji niemieckiej na tejże platformie mogą otrzymywać powiadomienia o udostępnieniu nowych materiałów. Twórcy remakeów chętnie wykorzystują też funkcję Instagram Stories, która jeszcze nie istniała, gdy powstawały pierwsze sezony Skam. W relacjach postaci pojawiają się zdjęcia i filmy, dodatkowo wzmacniające poczucie autentyzmu. Choć są wykonane wcześniej, to na Instagrama trafiają w czasie rzeczywistym i korespondują $\mathrm{z}$ tym, co widzowie mogą oglądać w poszczególnych klipach. Zmiany w sposobie komunikacji wewnątrz serialu oraz podawania treści widzom odzwierciedlają zmieniające się sposoby użycia nowych mediów w docelowej

[19] R. Donadio, Will 'Skam,' a Norwegian Hit, Translate?, „The New York Times” 9.12.2016, $<$ https://www.nytimes.com/2016/12/o9/arts/ television/will-skam-a-norwegian-hit-translate. html>, dostęp: 16.08.2020.

[20] Post Julie Andem w serwisie Instagram Z 10 listopada 2017 r., <https://www.instagram. com/p/BbU84w1gCtI/>, dostęp: 16.08.2020. 
grupie wiekowej, która dziś chętniej używa Instagrama niż Facebooka[21].

Obecnie wszystkie remaki zaczynają wkraczać na niezbadany teren. Niektóre, jak holenderski Skam NL, zakończyły już swój bieg. Ewenementem pozostaje na ten moment Skam France, który jako pierwsza adaptacja Skam wykroczył poza materiał źródłowy w piątym i szóstym sezonie. Była to swoista próba ognia, która udowodniła, że kontynuowanie na własną rękę historii wykreowanych przez Andem pozostało dla widzów równie pociągające.

\section{Potencjalna przyszłość formuły}

Przyszłość uniwersum Skam pozostaje niejasna. Co jakiś czas pojawiają się pogłoski o kolejnych możliwych remakeach, w tym także o ewentualnym powstaniu wersji polskiej. Mimo stałej aktywności grupy wiernych fanów nasuwa się jednak pytanie, ile razy można oglądać prawie identyczne historie zanim się one znudzą?

Wielu trudności przysparzają także umowy licencyjne, które wpłynęły na sposób, w jaki międzynarodowa publiczność mogła docierać do treści związanych z oryginalnym Skam. Każdy kolejny remake musi zmierzyć się z tymi samymi problemami prawnymi, a konieczność obchodzenia zabezpieczeń może dodatkowo zniechęcać potencjalnych odbiorców.

Sama marka Skam ma się jednak dobrze, czego dowodem może być wydany również $\mathrm{w}$ Polsce czterotomowy zbiór oryginalnych scenariuszy serialu autorstwa Julie Andem, stanowiący jego przedłużenie $\mathrm{w}$ kolejnym medium. Wszystkie zakończone już wersje serialu zostawiają po sobie swoiste internetowe cmentarzysko - nieaktywne już profile postaci, gdzie wciąż dostępne są „ich” posty i zapisane Instagram Stories. Pod zdjęciami na instagramowych kontach bohaterów norweskiej wersji prawie codziennie pojawiają się nowe komenta-

[21] D. Green, The most popular social media platforms with Gen Z, „Business Insider” 2.07.2019, <https://www.businessinsider.com/gen-z-loves-snapchat-instagram-and-youtube-social-media-2019-6? IR=T>, dostęp: 16.08.2020. rze stęsknionych widzów, przypominając o niezwykłym zaangażowaniu publiczności w życie tych postaci.

Nie ulega wątpliwości, że stacja NRK trafiła na prawdziwą żyłę złota, najpierw eksperymentując, a potem doskonaląc transmedialną narrację skierowaną do grupy najbardziej podatnych na ten sposób opowiadania odbiorców. Młode pokolenie korzysta jednocześnie $\mathrm{z}$ wielu urządzeń oraz z rozmaitych mediów społecznościowych, bezustannie funkcjonując $\mathrm{w}$ przestrzeni wirtualnej. Trzymając rękę na pulsie i rozmawiając $z$ nastolatkami o ich problemach i oczekiwaniach, można dostosowywać się do wymagań publiczności i proponować coraz to nowe rozwiązania na gruncie transmedialności. W przyszłości możemy się z pewnością spodziewać kolejnych prób takiego prowadzenia fabuły. Kwestią dyskusyjną pozostaje jednak, czy uda im się powtórzyć sukces Skam. Norweski serial pozostanie bowiem tytułem, który przetarł drogę innym tego typu produkcjom.

\section{B I B L I O G R A F I A}

Bartleet L., Why you should be watching Skam, Tumblr's most talked-about TV show of 2017, „NME” 2017, $<$ https://www.nme.com/blogs/tv-blogs/watching-skam-tumblrs-talked-tv-show-2017-2168642>

Donadio R., Will 'Skam,' a Norwegian hit, translate?, „The New York Times” 2016, <https://www.nytimes.com/2016/12/09/arts/television/will-skam-a-norwegian-hit-translate.html>

Eggesvik O., Nå har Oslo fått sitt første rødgrønne budsjett på 19 år, „Aftenposten”, 2016, <https://www. aftenposten.no/osloby/i/8M7bW/naa-har-oslo-faatt-sitt-foerste-roedgroenne-budsjett-paa-19-aar>

Fandalen J.I., Nerven $i$ „Skam” skal vore sterk og relevant, „Rushprint” 2016, <https://rushprint.no/2016/04/ nerven-i-skam-skal-vaere-sterk-og-relevant/>

Green D., The most popular social media platforms with Gen Z, „Business Insider” 2019, <https://www.businessinsider.com/gen-Z-loves-snapchat-instagram-and-youtube-social-media-2019-6? IR=T>

Jenkins H., Kultura konwergencji. Zderzenie starych i nowych mediów, przeł. M. Filiciak, Warszawa 2007

Jørgensen K.K., Mener „Skam” burde vore pensum, „NRK”, 2016, <https://www.nrk.no/livsstil/mener-_skam_-burde-vaere-pensum-1.12959025>. 
Leszkiewicz A., Skam, interrupted: why is the phenomenally popular teen drama ending before its peak?, „New Statesman" 2017, <https://www.newstatesman. com/culture/tv-radio/2017/06/skam-interrupted-why-phenomenally-popular-teen-drama-ending-its-peak>

Leszkiewicz A., Skam: how one Norwegian teen drama got the TV depiction of sexual assault right, „New Statesman" 2017, <https://www.newstatesman. $\mathrm{com} /$ culture/tv-radio/2017/03/skam-how-one-norwegian-teen-drama-got-tv-depiction-sexual-assault-right>

Max D.T., „SKAM”, the radical teen drama that unfolds one post at a time, „New Yorker” 2018, <https:// www.newyorker.com/magazine/2018/06/18/skam-the-radical-teen-drama-that-unfolds-one-post-at-a-time>
Nilsen K.S., Elnan C., Why NRK can't translate Skam, „NRK” 2016, <https://www.nrk.no/kultur/why-nrk-can_t-translate-skam-1.13208362>

Taylor T., How Skam's Isak and Even revolutionized teen TV, „Interview Magazine” 2017, <https://www. interviewmagazine.com/film/skams-isak-even-revolutionized-teen-tv>

Tired I., Fjelletveit I., Skam-skuespillerne møtte William og Kate. Men hertugparet hadde neppe sett serien, "Aftenposten" 2018, <https://www.aftenposten.no/ verden/i/MgLRkK/skam-skuespillerne-moette-william-og-kate-men-hertugparet-hadde-neppe-sett-serien>

Woldsdal N., Michelsen I., Skam slår alle rekorder, „NRK” 2016, <https://www.nrk.no/kultur/skam-slar-alle-rekorder-1.13282929> 